Article received on 11 September 2013

Article accepted on 30 November 2013

UDC

\title{
POPULAR MUSIC, SOCIAL PROTEST AND THEIR SEMIOTIC IMPLICATIONS
}

\section{Dario Martinelli*}

International Semiotics Institute

Lithuanian Academy of Music and Theatre

\begin{abstract}
The goal of this article is to discuss the relationship between popular music (song writing, in particular) and issues of social protest, as portrayed in the various repertoires. The interface of the analysis is of a semiotic type, and the steps will follow a path that goes from problematizing the issue as such (with an emphasis on the current difficulties of identifying protest songs in terms of "genre"), to the definition of those stylistic elements pertaining to the context (in/for which these songs are written and/or played), the themes (as appearing from the lyrics) and the music itself (with the implication that the latter aspect is normally underrated in its significance, within such a process).
\end{abstract}

\section{Introduction}

The discussion around "protest songs" in popular music has been, and still is, at once rich and, to an extent, incomplete. If the literature on the subject is ample and authoritative, ranging from song-by-song ${ }^{1}$ to genre-by-genre ${ }^{2}$ analyses, plus more organic reflections ${ }^{3}$, on the other hand, the role of "music" as such has never been given the prominent role that I shall instead try to confer here. This article is the fourth 'upgrade' of a research path that I started in 2004, comprising some insights on the notion of "protest songs" as a musical genre. My attempt, here, is to sum up the various reflections in a more systematic manner.

\footnotetext{
* Author contact information: dariomartinelli.eu@gmail.com

${ }^{1}$ See, for instance, Edith Fowke, Joe Glazer. Songs of Work and Protest, New York, Dover Publications, 1973.

${ }^{2}$ See Ray Pratt, Rhythm and Resistance: Explorations in the Political Uses of Popular Music, Westport, Praeger, 1990.

${ }^{3}$ See Dorian Lynskey, 33 Revolutions per Minute, New York, Ecco, 2011.
} 
Problems, and therefore opportunities, start already from the expression that is normally employed to describe these repertoires: "protest songs", which may benefit from a little implementation. I shall begin from a far worse expression: the Italian "canzone impegnata", often used as an alternative to the more exact "canzone di protesta". "Canzone impegnata" means "committed song", with the implication of a political type of commitment, but of course the expression is rather superficial. Music can be useful to society also in other forms (would it not be fair, for instance, to call "committed" Paul Simon's or Peter Gabriel's efforts to let their audience become acquainted with non-western music?), and, in addition, there are dozens of "protest" songs that are simply not committed to doing anything at all, and explicitly so, since their goal is exactly that of showing a lack of interest in a society that appears rotten and impossible to fix.

However, "protest", too, shows its flaws. How else, indeed, should we call songs like The Clash's "Train in Vain" or Alanis Morrisette's "You Oughta Know", which are clearly songs of protest, except that they protest against their cruel partner/lover? "Protest" may be the only word that manages to keep, in the same group, descriptions of and prescriptions for a wrong or just society, leftist or rightist musicians, songs of revolution, reaction or resistance, but nobody prevents us from applying the same attitude to private and intimate matters, unrelated to the conventionally shared idea of the repertoires we are dealing with, here.

A second common denominator, to place along with "protest", is possibly needed, and I suggest adding the adjective "social". With "songs of social protest", we are able to underline the equally important aspects of the "explicit disapproval" of a given state of things (protest), and the "social" dimension of the latter. Other distinctions, besides these, are not too relevant, as a "song of social protest" (SSP, from now on) can feature a number of diverse, even contradictory, characteristics, and yet remain such. There are aggressive and pinpointed SSPs, but also quiet and diplomatic ones, up to soft and corny ones, like "We Are the World". SSPs do not necessarily have a standard political color, and may easily be leftist, rightist or even anti-political (in fact, the latter option possibly constitutes the majority of SSPs). It may look forwards, backwards, or to the hic et nunc. And finally, it may be coherent and "committed" (in the Italian way), or it may rather sound like a Facebook user thinking that pressing "Like" to the picture of an abandoned dog or a starving child is enough to make him/ her a person of virtue. Obviously, the establishment of thresholds of analytical depth or intellectual honesty is not our problem (unless we want to get rid of the majority of the most celebrated protest singers: wife abusers singing feminist songs, rich superstars singing about poverty, 1400 hectares property owners singing "Make a little space, make a better place", and so on). 
In the end of the day, the adoption of the expression SSP is not unlike Dorian Lynskey's idea that a protest song is "a song which addresses a political issue, in a way which aligns itself with the underdog"4

\section{Songs of social protest as a "genre": the challenges}

If, in popular music studies, notions like performance, multimodality, multimediality and others have become more central than the 'good, old' debate on styles and genres, it should not be forgotten that significant instances of research in this area are still being published, and scholars like Borthwick ${ }^{5}$ or Holt $^{6}$ have certainly kept the discussion lively and fresh. At the same time, it is fair to say that the search for a commonly shared idea of a semantic and operative concept of the notion of "genre" is far from over. This is due first of all to different subjective demands: genres are important for the musicologist, sure, but also for the music critic who needs to decide how a certain work/ artist has to be reviewed (someone like Sting may be assigned indifferently to the rock or the jazz column, and - after Songs from the Labyrinth, released in 2006 for Deutsche Grammophon - to the classical column too); for the young band opening their page on MySpace (what music do we really play?); for any branch of the music industry (is it legitimate, say, that Grammy Awards have created, as they did, two separate prize categories for "Rap" and "Rap with singing"?), etc.

Secondly, it is popular music as such, that is in constant development, and that of course is reflected on the genres too. It is a common practice that new musical (and/or social) events are circumscribed through the creation of a new genre, the latter eventually establishing a case that remains codified even when the event fades away. Britpop was in actual fact active during the 1990s, but it subsequently became a comfortable label to classify a number of more recent British bands whose stylistic features are vaguely reminiscent of bands like Blur, Oasis or Suede. Not to mention all those styles that (via an even minimal aesthetic development or refinement) result in a post-something that becomes in itself a genre (post-rock, post-punk, post-tango...).

Finally, there is the never-ending question of the legitimacy in principle of stylistic classifications, and in this case one may move from populist, antiideological positions like the one attributed to Duke Ellington ("There are only two kinds of music: the good and the bad"), to straight refusals of musicology,

\footnotetext{
${ }^{4}$ Dorian Lynskey, op. cit., xiv.

${ }^{5}$ Stuart Borthwick, Popular Music Genres, Edinburgh, Edinburgh University Press, 2004.

${ }^{6}$ Fabian Holt, Genre in Popular Music, Chicago, Chicago University Press, 2007.
} 
as such ("Writing about music is like dancing about architecture", this one attributed to Elvis Costello) ${ }^{7}$.

In all this, it is interesting to notice how the SSP repertoires were hardly, if ever, taken as a "genre", either institutionally or theoretically. There are no Grammies awarded to the "protest song of the year" and students browsing the history books on popular music in search of Jor Hill or Pete Seeger, will more likely find them under "American folk singers".

What is this reluctance about? I believe it relates to two more basic questions: 1) The more general reluctance, within such taxonomic enterprises, to identify genres on the basis of the themes of the lyrics; 2) Another general reluctance to identify genres in a political and ideological sense.

It is quite true that, unlike literary or cinematographic genre classifications, the musical ones are not particularly eager to place linguistic and thematic aspects at the center of attention. If we quickly browse the names of the main genres, we notice that the lion's share goes to categorizations of a musical, or at least aesthetic, nature: we find references to music, as such (Prog, Boogie, Melodic Pop...), to music as art (Experimental Rock, Art-Rock...), to the instrumentation employed (Synth Pop, Acoustic Pop, Electronica...), to the venues of performance (Arena Rock, Club Music, Pub Rock...), etc.

However, exactly the latter example produces a potential hypertext. Expressions like Club Music or Pub Rock do not refer only to music (as in: "where that type of music could/should be played"): more relevantly, they refer to a context, and that $i s$ a departure from music. Indeed, the contextualization of music is a rather common form of genre classification, as we can find hints about geography (Philadelphia soul, Delta blues, Mandopop...), social occasions (lounge, surf, skate punk...), emotional states (blues, soul, goth...), and so on, increasingly shortening the distances between music and lyrics. Let alone the vast, complex universe of blues (a genre that is richly codified both musically and thematically), we find for instance that genres like gothic rock are distinguished from other sub-categories of rock on the basis of the introspective, dark and pessimist atmosphere of the lyrics: that is what justifies the word "gothic", certainly not the music, which sounds neither like a horror movie soundtrack, nor like Gregorian chant.

\footnotetext{
${ }^{7}$ A rather unfortunate joke, I must say. As all the insiders of the two arts know very well, indeed, dance and architecture are closely related, in that they share most of their main concerns (and concepts of those): space, movement, objects' composition... To compare the dance and architecture to writing and music is thus a good argument to legitimize musicology, not dismiss it. Thank you Elvis, on the behalf of the category!
} 
That also means that it is not necessarily true that genre classifications are always alien to ideological reflections. In fact, it is popular music itself that is perfectly apt to be analyzed this way (Middleton's classics have made that clear for decades, already ${ }^{8}$ ). In a genre like punk (which already comes to life as an ideological statement), we find a significant amount of sub-genres formulating their artistic paradigm in ideological terms. Anarcho-punk, Nazi-punk, Christian punk... save the common musical identity (punk, indeed), the real difference lies in the political, religious, philosophical stands taken by the respective musicians, through their lyrics, first of all, but also through their attitudes, looks and public statements. The same applies to many other genres, especially if we do not confine ourselves to the so-called mainstream. There are also cases when various musicians organize themselves in groups and platforms of a political/ ideological nature: see the neo-Nazi Rock Against Communism or the leftist Rock In Opposition.

\section{Songs of social protest as a "genre": the opportunities}

So: can we say anything relevant about SSPs, in a strictly musical sense? To begin with, the historical presuppositions of the SSP, in terms of conceptualization, are not unlike those of film music, liturgical repertoires or muzak. That is: SSPs originate from the need to support events and manifestations of social protest. While it is true that nowadays we can find a SSP written by a musician who has no particular inclination to political activity, released on an album that has no other goal than to be purchased and listened to at home, not the same can be said about the vast majority of the early SSPs, until at least the 1960s. As a matter of fact, these songs were appositely written for strikes, labor union gatherings, public demonstrations, sit-ins, up to more recent charity or awareness raising events.

SSPs, just like soundtracks or gospels, are therefore a form of functional music, and - as such - must be subject to some sort of musical codification. The author, for instance, must keep in mind that his/her song a) might be performed by people without a professional familiarity with music; and b) should be easy to memorize, with a clear and reproducible message, and with the capacity to create or enhance group feeling. Now, these are all musical problems, not only lyrical ones (or else, it should be possible to write a simple message like "We shall overcome one day" with a melody that covers four octaves, is in 5/4 and employs microtones, and still expect it to become one of the most popular SSPs

\footnotetext{
${ }^{8}$ See, for instance, Richard Middleton, Studying Popular Music, Philadelphia, Open University Press, 1990, or Voicing the Popular: On the Subjects of Popular Music, London, Routledge, 2006.
} 
of all times). My first contribution to this discussion ${ }^{9}$ was exactly devoted to those musical elements/strategies that contribute to a "successful" SSP:

1) Use of a common and easy-to-carry instrumentation: acoustic guitars, light percussions (or even improvised ones, such as handclapping), harmonicas... The key, here, is to let these instruments appear also in the recorded version of the song, in order to let the non-professional musicians know that "this is how the song sounds anyway". The reason why tracks like "Blowing in the Wind" or "Give Peace a Chance" are so effective in their purpose lies precisely on the fact that, on record, they sound already like an improvised performance on a street, during a demonstration;

2) Use of simple and accessible harmonic structures: no difficult keys like F sharp or E flat, no complicated chords and not many of them, basic chord progressions... The prototypical SSP is in D, or G, or C major or E or A minor; the appearance of a augmented or generally "jazzy" chord is an event as rare as the Halley's comet; and the usual progressions are of the cadenza-type (I-V, I-IV, I-IV-V-I, I-vi-IV-V, etc.);

3) Use of basic rhythmic structures: from the supreme synthesis of the hand clapping on the upbeats (not downbeats, please: that is for the Radetzky March), to the slightly more complex interaction of hands and feet, as in the case of Queen's "We Will Rock You" (a very interesting case, because this song is not a SSP, and yet it is often employed in events of social protest - we shall see why). Light percussions (tambourines in particular) or whole drum-kits are of course welcome, too: the point is in the simplicity of the pattern as such (which means, among other things, an almost untouchable preference for $4 / 4$ non-syncopated structures);

4) Catchy hooks and/or refrains: the refrain (in the typical strophe-refrain format, very often employed in SSPs) or the chorus (in the less recurrent chorusbridge setting) are certainly the parts to handle with more care: the impact of the song on the public largely depends on their musical accessibility. Those, once taken care of, other choices are possible: a liturgical structure (with a "master of ceremonies" who sings the more complex strophes and the "community" that joins in the refrains - as in "Give Peace a Chance"); a choral piece from start to end (like "We Shall Overcome"), and so forth;

5) Culturally connoted (and recognizable) sound: also because of what we already listed, a recorded version of an SSP could already feature an "acoustic" feel, an "ethnic" atmosphere, or anyway something that is reminiscent of the genres and authors that already have a reputation in the SSP field. Many of my

\footnotetext{
${ }^{9}$ Dario Martinelli, “S for Singalong”, in G. Ipsen, M. Bauters, D. Martinelli (eds.), Semiotics from $S$ to $S$, Helsinki, Umweb, 2004.
} 
generation will perfectly remember the appearance of Tracy Chapman, within the panorama of 1980s' super-productions, alone on the stage, with the sole support of a folk guitar, singing songs like "Talkin' About Revolution". Her credibility as an SSP performer proceeded also (if not mostly) from the fact that she immediately recalled the likes of Joan Baez, while the music landscape of those days was filled with synthpop, LinnDrum sounds and Ibanez guitars with tons of effects.

So: at least the traditional SSP seems quite suitable for a musical classification. As we shall see, its identity as "functional music" plays a relevant role in my reflections. In the following pages I shall attempt to draw an analytical model for SSPs, which would take into account three crucial aspects: context, contents and music. Like all forms of categorization, this one too is far too generic for me to claim that the whole complexity of the problem has been grasped: the idea, more humbly, is simply that of tracing a few relevant paths into a very foggy and heterogeneous landscape.

\section{Songs of social protest and context}

When, where and why a SSP is written/performed shall be the first step of the model. If the analysis of a soundtrack is inseparable from the movie that it accompanies, it should be equally difficult to keep the distances between a song like "The Preacher and the Slave" and the Industrial Workers of the World, or between "Bella ciao" and the Italian civil war (Resistenza). What type of relationship does exist between a SSP and its context (which could be either "innate" or acquired in time)?

A significant answer to this question was given by one of the founders of musical semiotics as a field, Gino Stefani ${ }^{10}$, who suggested three different types of singing activity to be performed within an event of social protest. I took the liberty to slightly re-adapt the model to our purposes, but the substance is still faithful to Stefani's original formulation:

1) Ad hoc, or focused, song - It is specific of the circumstances that caused the event: the song's lyrics talk about such circumstances, and it is not unusual that it may be one of the event's participants to actually write them ${ }^{11}$. To give a

\footnotetext{
${ }^{10}$ Gino Stefani, "Canzoni e difesa popolare nonviolenta", in A.Drago and G.Stefani (eds.) Una strategia di pace: la difesa popolare nonviolenta, Bologna, FuoriThema, 1993.

${ }^{11}$ That was for instance the case with the likes of Joe Hill, Pete Seeger, Woody Guthrie, Phil Ochs and others, whose life was equally divided between musical career and political activism. If they went to a demonstration, most of the times you could be sure they would go with a new song.
} 
famous example: if the context was a demonstration against Apartheid, a song like Peter Gabriel's "Biko" would be an ad hoc choice;

2) Area, or general, song - The song, in this case, is pertinent but not typical of the context: lyrics cover the subject in a more general manner. To keep up with Gabriel's beautiful song, "Biko" could still be employed in a demonstration against racism in - say - the United States, but in this case its pertinence would be indeed more general (Stephen Biko, notoriously, was a South African anti-Apartheid activist);

3) Phatic, or generic, song - In this rather peculiar case, the song may actually not be an SSP, strictly speaking, but it may become one on the basis of its employment within a given event. As Roman Jakobson's well-known formulation of the "phatic function" of language goes, the idea is that this kind of song serves more for the purpose of enhancing contact and group feeling among the participants in the event, rather than describing the latter's themes. Funnily enough, thus, in the very field where topics and contents seem to be indispensable, we find a type of SSP pro tempore where lyrics are almost irrelevant, and what matters is the song's ability to create "the right atmosphere". This is why a song like "We Will Rock You" (or "Let It Be", to mention another recurrent case) is not an unlikely choice among the participants in an event of social protest.

What we find here, at this point, is an enlarged perspective of what an SSP is or can be. I certainly do not wish to carry this notion to an extreme that would trivialize it (an extreme of the "anything goes" type: obviously, songs like "Stayin' Alive" or "Walk Like an Egyptian" are not likely ever to be heard at a political demonstration). What is relevant, here, is to state clearly that the SSP is a relatively flexible semantic field that can be restricted or expanded thanks to this third element, the context, which proceeds in parallel motion with the music and lyrics.

Once again, let us not be surprised by this, because it is exactly what happens in the field of functional music. Sure, Hermann or Morricone would write original and specifically filmic music, but so many directors (Kubrick, Lynch, Kaurismäki...) were eager to recontextualize existing music that was created for other purposes. Strauss' "Einleitung" from Also sprach Zarathustra is a great piece in its own right, but how many people will resist the temptation to think about Space Odyssey while hearing it? 
Martinelli, D.: Popular Music, Social Protest and Their Semiotic Implications (41-52)

\section{Songs of social protest and contents}

In one of my previous studies ${ }^{12}$, I had had the opportunity to underline that the historical development of SSPs was brought to completion during the 1960s, when the appearance of a new approach to contents established the overall dominance of three main typologies of lyrics:

1) Classic type. Possibly the most prototypical one, the classic SSP is the one that we may associate with a young Bob Dylan with a guitar and harmonica, or an older Woody Guthrie with a cigarette and the inscription "This machine kills fascists" on his guitar. The classic SSP offers a fundamentally analytical approach, with the clear intention to discuss a topic in a detailed and focused way (as in the Talking Blues songs of Guthrie and Seeger, the parodies of Joe Hill, several European singer-songwriters, etc.). In reference to its context, the classic SSP is often an ad hoc song, as it normally refers to a real, specific circumstance. In this sense, it often produces a "here and now" type of message, though the latter can of course be generalized and applied to more contexts. Finally, the analytical inclination is often better conveyed through a strophe-refrain structure, which allows a thorough description of the theme in the strophes and a "tagline"-styled prescription in the refrain: in short, the classic SSP wants the listener to "know" and to "act".

2) Spiritual type. Along with the classic model, there is always the strong genetic connection that many forms of popular music bear with early AfroAmerican repertoires, such as spiritual, gospel and blues. These songs have indeed a "spiritual" component (not necessarily in the religious sense of the word), as their main "action plan" is that of asking (or, indeed, praying), waiting and hoping that things will improve. They tend to be rich in metaphors, usually inspired by sacred texts (as in spirituals) or even private relationships (so many times blues has used the guise of a love story to actually address the society). From these roots have derived several other genres, or specific songs, which employ a similar attitude: emotionally involved but operatively passive (whereas, generally speaking, one could say that the classic SSP tends to be intellectually involved and operatively active). A typical example of the spiritual SSP is of course "We Shall Overcome", but the perfect one, in my opinion, is Cat Stevens's "Peace Train". It is indeed most significant that the protagonist of that song is waiting for the peace train, promising everyone that, one day, that train will arrive. As a rhetorical device, the train can be employed in a much

\footnotetext{
${ }^{12}$ Dario Martinelli, Authenticity, Performance and Other Double-Edged Words. Essays in Popular Music, Helsinki/Imatra, International Semiotics Institute, 2010: 163-182. I also remind to this study for a discussion on the origins of, and reasons behind the emergence of this new lyrical model, which, as I specify later, I call "Hippie type".
} 
more active way: Stevens could have invited the world to jump on the locomotive of that train, and drive it towards the peace station (or something like that: of course, one can be more poetic that this). On the contrary, Stevens opts for the spiritual choice: he waits and he hopes. Due to this approach, the main tendency of spiritual SSPs is that of being general or phatic, addressing wider instances and themes. For the same reason, even though the strophe-refrain remains a favorite choice (but this is also due to the fact that, in general, stropherefrain songs are statistically the most recurrent lyrical model), the number of chorus-bridge templates increases considerably ("We Shall Overcome" itself, Marvin Gaye's beautiful "What's Going On", etc.). As mentioned, lyrics are employed to "ask" and "hope": the spiritual SSP wants the listener to "have an idea" (rather than knowing specifically) and to "have faith".

3) Hippie type. While the first two categories appear already in the very early examples of SSPs, this third one is exactly the result of the abovementioned new approach developed during the 1960s. It is in that period, indeed, that a significantly less analytical type of song emerges: The Beatles, and the post-Beatles John Lennon, are probably the best known cases, but of course there are several other instances, including Creedence Clearwater Revival ("Have you ever seen the rain?"), Queen (“One Vision"), Lenny Kravitz ("Let Love Rule"), many songs crafted for charity events, etc. The hippie SSP tends to adopt an anti-ideological, or even nihilist, lyrical approach, and the songs always need to be contextualized by the listener, rather than by the author (who always avoids being too circumstantial). Taglines like "All you need is love" or "All we are saying is give peace a chance" are launched, and it is up to the audience to decide when and where the message is to be applied. Evidently, this path is just the opposite of classic SSPs, which instead prefer to discuss/describe events circumscribed in space and time, which can be eventually generalized. From the 1960s onwards, it is like people feel that, first and foremost, all they need is love, and then, in a second moment, they find themselves thinking that the Vietnam War should be ended, that racial discrimination is unjust, etc. The hippie SSP, thus, tends to be general or phatic, anti-ideological, and universal in message. More often than not, it employs a strophe-refrain template, inclining the strophes to neglect/oppose analysis and ideologies ("There's nothing you can do that can't be done, nothing you can sing that can't be sung...") and the refrain (this time, just like the classic SSP) to prescribe and encourage to action. In other words, the listener is invited "not to waste time" and to "act". 
Martinelli, D.: Popular Music, Social Protest and Their Semiotic Implications (41-52)

\section{Songs of social protest and contents}

Let us return to music per se. With the usual disclaimer that this categorization, like all others presented here, has no pretension to be a faithful photography of the various nuances of this complex question, the idea, here, is to emphasize a reasonable amount of stylistic features, so that a paradigm can eventually be drafted. Once again, being a functional form of music, the SSP has every right to be differentiated musically, for the same reason that film music may contain, at the same time, John Williams' epic themes, Vangelis' synthesizers and Miles Davis's experiments on Frantic.

Five, this time, are the areas I intend to focus on:

1) Simple SSP. The most typical one, it is often intended for direct employment in events of social protest, and tends to fall into the already discussed prototype of simple instrumentations, catchy melody, easy rhythmic patterns, etc.: it is most often found in genres like country, world, blues, and others with a distinctive folk matrix. For instance, most of the classic American protest singers are identifiable in this area: Pete Seeger, Josh White, Woody Guthrie, Joe Hill...

2) Solemn SSP. Typical of most charity events, it is the most radio-sexy and chart-friendly kind. It tends to have a mainstream, pop quality, with lavish arrangements and big productions. Songs like "All You Need Is Love", "Do They Know It's Christmas?", "We Are the World", which were indeed conceived for large scale events, bear such characteristics, but the principle can also apply to songs that were not necessarily written with that intent ("Biko", "They Dance Alone"...)

3) Aggressive SSP. Usually emerging from the underground/alternative scene, it is the kind that we find most often in genres like indie-rock or rap. It is recognizable from the "angry" attitude of both the music and lyrics. The repertoires of bands like Green Day, Public Enemy, Manic Street Preachers, and of course The Clash are very generous within the category.

4) Manneristic SSP. Less common and more peculiar, this type follows the postmodern charm of creating retro pastiches with a recognizable identity. The effectiveness, as SSPs, of songs like Tears for Fears' "Sowing the Seeds of Love" or the mentioned "Talkin' about Revolution", lies most of all in their respective reminiscence of The Beatles and Joan Baez, two very well-known acts often associated with SSPs.

5) Personal SSP. This last category works as a black box to store all those pieces which, rather than following a recognizable style, tend to reflect the personal artistic paradigm of single authors. The singer-songwriters' movement of different countries and epochs offers a rich variety of examples in this field. It 
is difficult to find a specific category for the anarchic sarcasm of George Brassens, the ambiguous theatricality of Algirdas Kauspedas, the nonsensical eclectism of Rino Gaetano.

To conclude: no part of the model is alien to grey areas and flexibility (e.g., if the context changes, contextual functions change too, as we have seen in the case of "Biko". Or: "Talking About Revolution" is "manneristic" if put in a historical perspective, but it can easily be classified as "simple" as well), and of course the three main groups (context, contents, music) are in constant interaction ("Sowing the Seeds of Love" is contextually "general", lyrically "hippie" and musically "manneristic", at the same time), Keeping in mind our initial warning against excessive trivializations, I dare suggest that this model may help a little to create a general understanding of the main conceptual and operative features of the SSP.

\section{References}

Fabbri, Franco, “A theory of musical genres: Two applications”, in D. Horn e P. Tagg (a cura di) Popular Music Perspectives, Göteborg and Exeter, International Association for the Study of Popular Music, 1981, 52-81

Denisoff, Serge, "Songs of Persuasion: A Sociological Analysis of Urban Propaganda Songs", The Journal of American Folklore, Vol. 79, No. 314, 581-589.

Denisoff, R. Serge, Sing a Song of Social Significance, Bowling Green, Bowling Green State University Popular Press, 1983.

Eyerman, Ron - Jamison, Andrew, Music and Social Movements: Mobilizing Tradition in the Twentieth Century, Cambridge: Cambridge University Press, 1998. 